\title{
Generalist-specialist continuum and life history traits of Central European butterflies (Lepidoptera) - are we missing a part of the picture?
}

\author{
Alena BARTONOVA ${ }^{1,2}$, JiRI BENES ${ }^{2}$ and Martin KONVICKA ${ }^{1,2}$ \\ ${ }^{1}$ Faculty of Science, University of South Bohemia, Branisovska 31, 37005 Ceske Budejovice, Czech Republic; \\ e-mails: al.bartonova@gmail.com; konva@entu.cas.cz \\ ${ }^{2}$ Institute of Entomology, Biology Centre ASCR, Branisovska 31, 37005 Ceske Budejovice, Czech Republic; \\ e-mail: BenesJir@seznam.cz
}

Key words. Lepidoptera, Czech butterflies, life history traits, generalist-specialist continuum, C-S-R strategies, voltinism constraint, population trend, Central Europe

\begin{abstract}
Analyzing life history traits of butterfly communities and faunas frequently reveals a generalist-specialist continuum as the main gradient, where species using wide arrays of resources, with good dispersal ability and fast development are distinguished from those using specialised resources, having limited dispersal ability and developing slowly. To ascertain the validity of the generalistspecialist approach for an intermediately species-rich Central European fauna, we analyzed ten life history traits for 136 species of butterflies currently occurring in the Czech Republic, using principal correspondence analysis (PCA) and controlling for phylogeny. The main gradient extracted indeed revealed a generalist-specialist continuum, while the gradient perpendicular to the main axis distinguished between small-bodied polyvoltine species feeding on small herbaceous plants and large-bodied monovoltine species feeding on grasses or woody plants. We coin "constrained voltinism continuum" for the second gradient and argue that it reflects the effect of anti-herbivore strategies of larval host plants on butterfly development. The position of the butterflies in the PCA ordination mirrors the C-S-R (Competitors - Stress tolerators - Ruderals) strategies of their host plants. Butterflies that feed on C- and R-selected plants tend to be generalists, but differ in voltinism, whereas specialists tend to feed on S-selected plants. Regressing measures of current conservation status of individual species in the Czech Republic against the two extracted life history gradients yielded a significant but weak response for the generalist-specialist continuum and no response for the constrained voltinism continuum. The weak responses were due to a wide scatter of status measures among "mid generalists". The generalist-specialist continuum is hence a rather poor predictor of species conservation status. Species of high conservation concern are found either among specialists, or among mid generalists with low to intermediate values on the constrained voltinism axis.
\end{abstract}

\section{INTRODUCTION}

Analyzing biotic communities with respect to the representation of constituent species' life history traits is a promising avenue of ecological research into the effect of environmental change on communities (McGill et al., 2006). Using butterflies as a model group (Boggs et al., 2003), recent authors have investigated changes in life histories, e.g., along altitudinal gradients (Stefanescu et al., 2011; Carnicer et al., 2013), in changing climates (Altermatt, 2010; Poeyry et al., 2009), under conditions of habitat loss and biotope fragmentation (Barbaro \& van Halder, 2009; Boerschig et al., 2013; Franzen \& Betzholtz, 2012), at large spatiotemporal scales (Mattila et al., 2006, 2008, 2011) and in restored habitats (Woodcock et al., 2012). Much research has also investigated positive or antagonistic relationships among individual traits, using measured or estimated values (Garcia-Barros, 2000; Cizek et al., 2006; Beck \& Fiedler, 2009; Garcia-Barros \& Romo, 2010; Turlure et al., 2010; Konvicka et al., 2012).

Many authors have reported that butterfly life history traits, particularly those associated with migratory capacity and exploiting new patches (Dapporto \& Dennis, 2013), combine into a continuum from generalism to specialism (e.g., Menendez et al., 2007; Ockinger et al., 2010; Lizee et al., 2011; Dennis et al., 2011; Carnicer et al., 2013; Soga
\& Koike 2013). Specialists tend to be sedentary, smallbodied, slowly developing, with few generations per year, utilising narrow trophic ranges and inhabiting discontinuous patchy habitats, whereas generalists tend to be mobile, large-bodied, rapidly developing with many generations per year, utilising broad trophic ranges and exploiting landscapes in a continuous manner (e.g., Koh et al., 2004; Komonen et al., 2004; Garcia-Barros \& Romo 2010). The two trait combinations lead to two opposite resource exploitation strategies: (a) inhabiting space continuously (as generalists do), or (b) forming spatially restricted colonies matching habitat patches connected by occasional migration (as specialists do). Traditionally, these two extremes are referred to as open versus closed populations (Warren, 1992).

Specialists are often assumed to be more threatened than generalists due to their association with scarce habitats (Komonen et al., 2004; Kotiaho et al., 2005; Barbaro \& van Halder, 2009; Carnicer et al., 2013) and poorer capacity for colonizing habitats (Lizee et al., 2011; Woodcock et al., 2012). However, this pattern does not hold universally. Generalists, often inhabiting human-transformed habitats such as farmlands and requiring larger areas to form selfsustaining populations, can be threatened by factors operating at larger scales, such as farmland consolidation (Ste- 
fanescu et al., 2011) or climate change (Menendez et al., 2007). Specialists, in contrast, may be pre-adapted to habitat fragmentation (e.g., selection against mobile individuals, Komonen et al., 2004) (Habel \& Schmitt, 2012; Habel et al., 2013). Consequently, specialists can be conserved by targeting their habitat patches, whereas conserving generalists may require land use adjustments over large scales (Rundlof \& Smith, 2006; Jonason et al., 2011). As shown by Dapporto \& Dennis (2013) for British butterflies, the currently most endangered species are "mid generalists", with intermediate positions on the generalist-specialist continuum, with too little dispersal ability for colonizing distant habitats and too high minimum area requirements to be able to survive in remnant habitat patches.

Other community ecology concepts relevant for butterfly life histories include, first, the $r$-K selection continuum (MacArthur, 1967; Pianka, 1970), where $r$-selected species, characterised by rapid population growth rates may correspond to generalists, whereas K-selected species, maintaining stable population sizes, may correspond to specialists (Stevens et al., 2012). However, large body size, presumably a K-selected trait, is associated with high mobility in butterflies (Walton et al., 2005; Sekar, 2012). Second, life histories of insects with herbivorous larvae may reflect the host plants' life histories, formalised as the Competitor - Stress tolerator - Ruderal (C-S-R) model of Grime (1977). While analyzing threat correlates of British butterflies, Dennis et al. (2004) observed that many declining species feed on $\mathrm{S}$ plants, tend to have narrow trophic niches and restricted mobility. Butterflies associated with $\mathrm{C}$ and $\mathrm{R}$ plants, on the other hand, should be relatively safe. Understanding the risks of generalisations based on the species poor British fauna, Dennis et al. (2004) called for investigations of the relationships between conservation status and life history patterns in other regional faunas.

Until now, extending the geographic scope for such analyses has been limited by restricted knowledge of species traits for species-richer faunas, by variation in life history traits across species ranges (e.g., latitudinal gradients in numbers of annual generations), or by lack of reliable data on changes in distribution. Apart from Britain, the existing analyses originated from species-poor Northern Europe (e.g., Kotiaho et al., 2005; Mattila et al., 2011), with the notable exception of Catalonia (e.g., Stefanescu et al., 2011).

In this contribution, we use the butterfly fauna of the Czech Republic to investigate the relationships between species life history traits and current threat levels. With 136 currently recorded species, the Czech Republic butterfly fauna is more than twice as rich as the fauna of Britain, and owing to its central position in Europe, it well represents the mid-latitudes of the continent (Dennis et al., 1991). An established recording scheme exists, as well as a satisfactory knowledge of species' life histories (Benes et al., 2002). We first use the life history traits of all Czech butterfly species to extract the main life history gradients structuring the fauna, and then ask how well the generalist-specialist continuum describes butterfly threat levels.

\section{MATERIAL AND METHODS}

\section{Species}

Czech Butterflies and Moths Recording [CBMR] collects butterfly distributional records from a variety of sources, expanding the scheme used for the distribution atlas by Benes et al. (2002). For this paper, we used 346,442 records from the years 2002 2013 (recent), and 240,281 records from the years 1951-2001 (past). We worked with 136 species currently (1995-2013) recorded in this country (Table 1), excluding nineteen nationally extinct species, together with the reintroduced Parnassius apollo (Linnaeus, 1758) and Lycaena helle (Denis \& Schiffermüller, 1775); two species of uncertain taxonomic status - Pyrgus trebevicensis (Warren, 1926) and Pieris bryoniae (Hübner, 1806); plus ten extremely rare vagrants, e.g., Argynnis pandora (Denis \& Schiffermüller, 1775) and Lampides boeticus (Linnaeus, 1767).

\section{Life history traits}

We worked with ten life history traits, mostly associated with dispersal and survival ability. Traits linked to dispersal were (1) body size, in terms of forewing length (from Higgins \& Riley, 1970); (2) mobility, or the propensity to disperse (from extremely sedentary to extremely mobile) (Reinhardt et al., 2007); (3) population density (adapted from area demand in Reinhardt et al. 2007), is the number of individuals that can occur per unit area of habitat (sparse to dense); (4) voltinism, or the average number of generations per year in the Czech Republic; (5) (summed) flight period (both from Benes et al., 2002), are assumed to be related to colonization ability (c.f. Boerschig et al., 2013); and the same applies to (6) range size (modified from Tolman \& Lewington, 2008). Traits likely to be associated with landscape scale survival were (7) fertility, defined as the number of eggs per female at eclosion (Reinhardt et al., 2007); (8) overwintering stage, indicating how early a species can reproduce in the season; (9) larval diet breadth (Benes et al., 2002; Tolman \& Lewington, 2008), following frequent observations that species with narrow host ranges tend to be more vulnerable (e.g., Koh et al., 2004; Mattila et al., 2008); and finally (10) host plant form, supposing that more apparent plants, such as trees and grasses, are both easily located and use different means of protection than non-apparent herbaceous plants (Cizek et al., 2006). All traits were coded in quantitative or ranked scales (see Table 1 for each species' values and Table 2 for scaling). For mobility, density and fertility, there were missing values for 34 species (Reinhardt et al., 2007). The missing density and fertility values were replaced by means for the respective traits; whereas for mobility, we used the expert assessment of the authors. To check influence of the missing values for fertility and density, analyses were then executed with only 102 species for which all trait values were available.

The final table of 136 species and 10 traits was analyzed by principal correspondence analysis (PCA), a linear ordination method that extracts major gradients of variation from a high number of intercorrelated variables, in CANOCO v. 5 (Ter Braak \& Smilauer, 2012). Butterfly species were individual samples, whereas their traits, which were centred and standardised to zero mean and unit variation, entered the analysis as "species data". For ordination with phylogenetic correction, we constructed a matrix classifying species to families and subfamilies, according to the literature and adjusted to recent knowledge (Eliot, 1973; Aubert et al., 1999; Caterino et al., 2001; Wahlberg et al., 2003; Braby et al., 2006; Warren et al., 2009, Table 1). Although not a proper phylogeny, this approach should suffice to separate the phylogenetic signal from analyses; we herein use the term "phylogeny" for brevity. This matrix was used as a covariate matrix for the phylogenetically constrained PCA. 


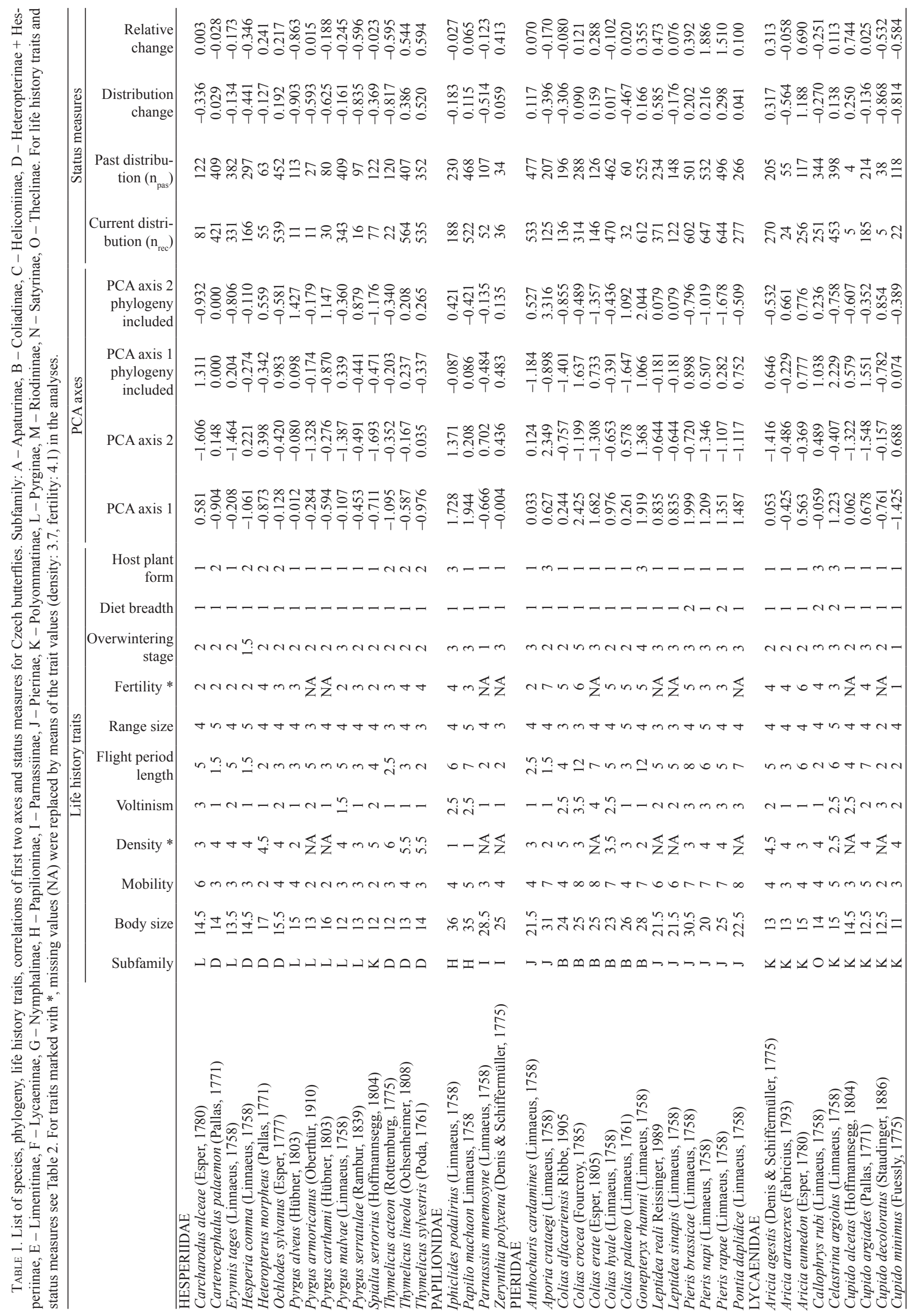




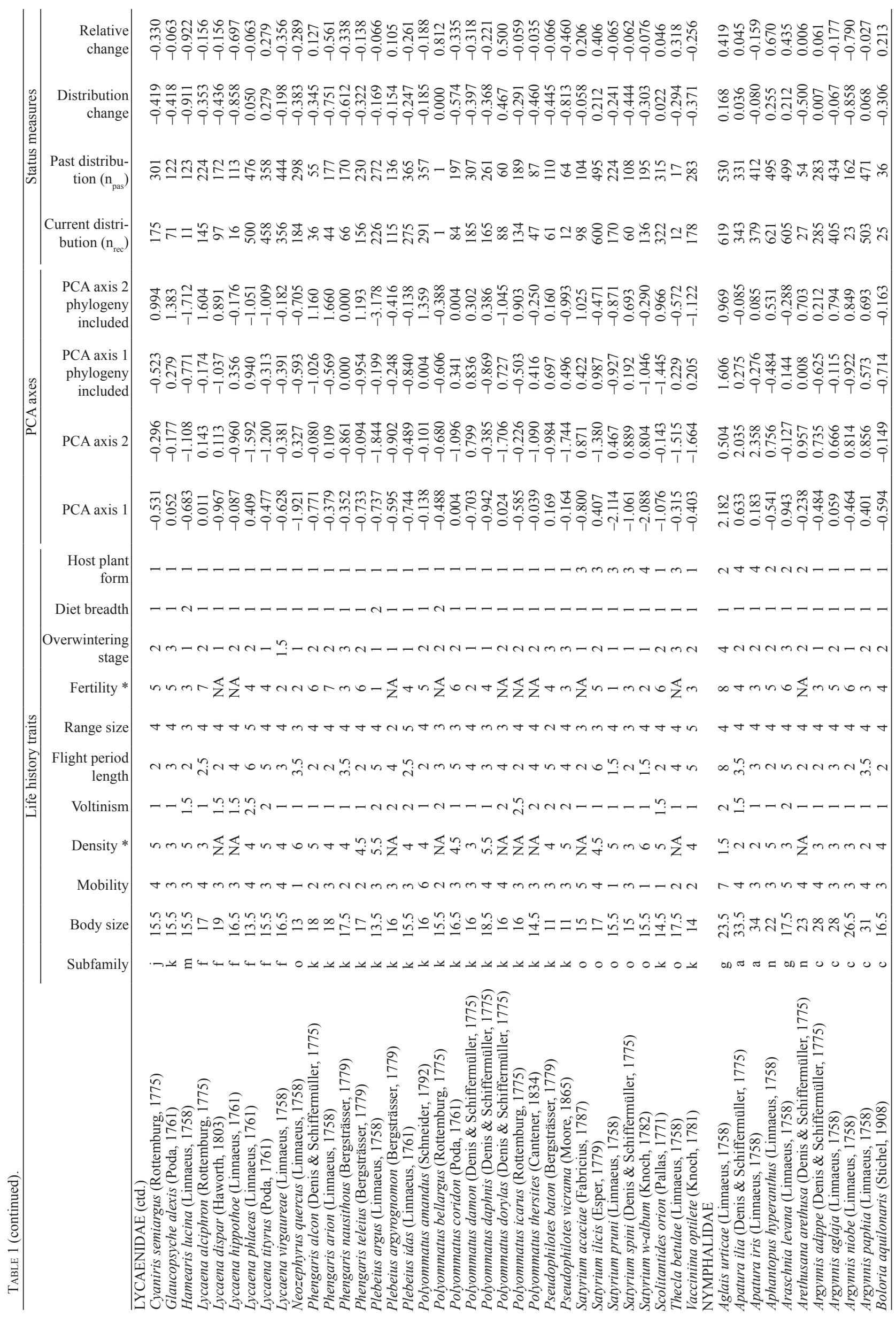




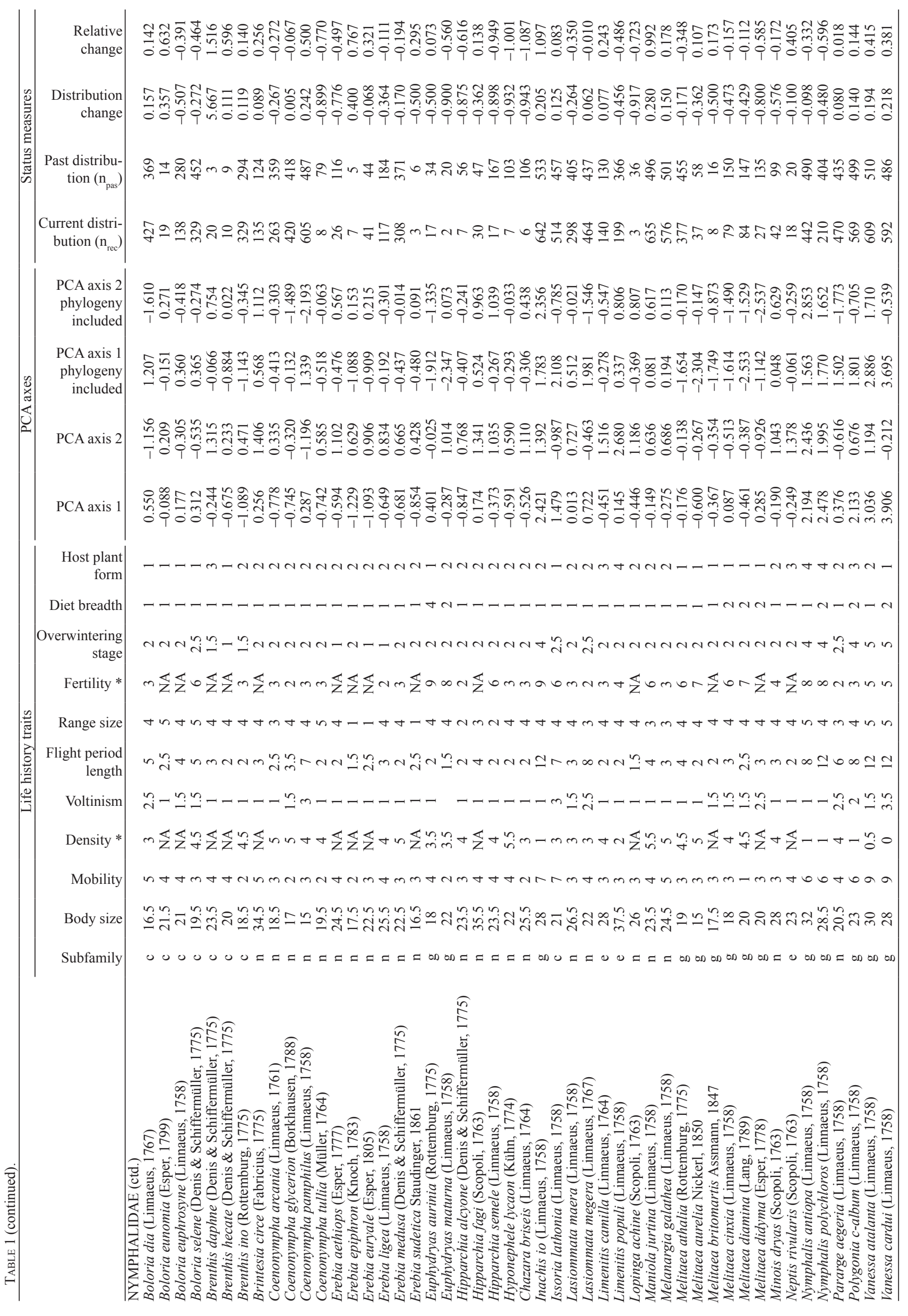


TABLE 2. The ten life history traits used in the PCA of 136 species of Czech Republic butterflies.

\begin{tabular}{|c|c|}
\hline Trait & Definition \\
\hline (1) Body size & Forewing length, absolute value $[\mathrm{mm}]$ \\
\hline (2) Mobility & $\begin{array}{c}\text { Tendency to disperse, ranked ( } 1 \text { - extremely sedentary, } 2 \text { - very sedentary, } 3 \text { - sedentary, } \\
4 \text { - rather sedentary, } 5 \text { - less sedentary, } 6 \text { - willing to disperse, } 7 \text { - mobile, } 8 \text { - very mobile, } \\
9 \text { - extremely mobile) }\end{array}$ \\
\hline (3) Density & $\begin{array}{l}\text { Ranked }\left(1-2 / \mathrm{km}^{2}, 2-6 / \mathrm{km}^{2}, 3-25 / \mathrm{km}^{2}, 4-1 / \mathrm{ha}, 5-4 / \mathrm{ha}, 6-16 / \mathrm{ha}, 7-64 / \mathrm{ha},\right. \\
8-260 / \mathrm{ha}, 9-1000 / \mathrm{ha})\end{array}$ \\
\hline (4) Voltinism & Average number of generations in Central Europe \\
\hline (5) Length of the flight period & Number of months in which adults occur (months of hibernation excluded) \\
\hline (6) Range size & $\begin{array}{c}\text { Categorized (1-smaller than Europe, } 2 \text { - size of Europe, } 3 \text { - as large as Western Palaearctic, } \\
4 \text { - Palaearctic, } 5 \text { - larger than the Palaearctic) }\end{array}$ \\
\hline (7) Fertility & $\begin{array}{l}\text { Categorization of the average number of eggs per female at eclosion }(1-19-27,2-28-39 \text {, } \\
3-40-57,4-58-82,5-83-119,6-120-173,7-174-250,8-251-363,9-364-527)\end{array}$ \\
\hline (8) Overwintering stage & 1 - egg, 2 - larva, 3 - pupa, 4 - hibernating adult, 5 - migrating adult \\
\hline (9) Diet breadth & Number of plant families fed on by larvae in the Czech Republic \\
\hline (10) Host plant form & $\begin{array}{c}1 \text { - ephemerals and small herbaceous plants, } 2 \text { - large herbaceous plants and grasses, } \\
\qquad 3 \text { - bushes, creepers and small trees, } 4 \text { - large trees }\end{array}$ \\
\hline
\end{tabular}

\section{Butterfly status measures}

To assess the relationships between life histories and conservation status in the Czech Republic, we regressed the individual species' positions in the trait ordinations against the following three status measures valid for the Czech Republic (Table 1):

(1) Current distribution: the numbers of $10 \times 10 \mathrm{~km}$ atlas grid squares with records of individual species in 2002-2013 ( $\left.\mathrm{n}_{\text {rec }}\right)$;

(2) Distribution change: the percentage change in the number of grid squares with records of individual species between 2002 2013 and 1951-2001: $\left(\mathrm{n}_{\text {rec }} / \mathrm{n}_{\text {past }}\right)-1$;

(3) Relative change: following the methodology of Telfer et al. (2002), which weights distribution changes by the sizes of the distribution range of a species, considering that, e.g., a 50\% loss from 2 originally occupied squares represents a smaller faunal change than $50 \%$ loss loss from 100 originally occupied squares. This method uses a linear regression relating proportions of grid cells with a recorded presence of a species (logit transformed) in the present versus past, i.e. $\operatorname{logit} P_{\text {rec }}=a+b \operatorname{logit} P_{\text {past }}$. Residuals of the fitted regression line are used as the relative values for individual species.

We regressed these three variables against the values on the first and second PCA axes, using generalised linear modelling in $\mathrm{R}$ version 3.0.2 ( $\mathrm{R}$ Core Team, 2013), following the information theory approach (AIC values, i.e. Akaike information criterion: Akaike, 1974) to distinguish between linear or more complex responses. We standardized both predictors and response values to zero mean and unit variance, used the Gaussian distribution of errors, fitted linear, quadratic and cubic functions, and selected the model with the lowest AIC value.

\section{RESULTS}

If not controlled for phylogeny, the four PCA axes explained $33.5 \%, 17.2 \%, 11.5 \%$ and $10.3 \%$ of the variation in 10 life history traits of 136 butterfly species. Axis 1 (Fig. 1 upper row, Table 1) correlated positively with mobility (correlation coefficient: 0.800 ), overwintering stage $(0.795)$, length of the flight period $(0.822)$, voltinism (0.557), body size $(0.471)$, fertility $(0.392)$, range size (0.274) and diet breadth (0.242); it correlated negatively with density $(-0.764)$ and host plant form $(-0.037)$. Axis 2 correlated positively with host plant form $(0.735)$ and body size (0.690), and negatively with voltinism $(-0.567)$, density $(-0.379)$ and length of flight period $(-0.299)$; the remaining traits displayed only weak correlations. Axis 1 thus corresponds to the generalist-specialist continuum, with highly mobile, rapidly developing species with many generations per year, having long flight periods and attaining positive values; and sedentary, slowly developing univoltine species forming dense local populations and attaining negative values. Axis 2, which still explains a high

TABLE 3. Status measures for 136 species of Czech Republic butterflies related to positions of individual species on a generalistspecialist continuum (PCA axis 1 obtained by ordination of the species life history traits, Fig. 1). Results for best-fitting responses, selected according to the AICs from sets of models of increasing complexity and compared with the null model $y=0$.

\begin{tabular}{lcccccc}
\hline & Response & d.f. & $\mathrm{F}$ & $\mathrm{P}$ & $\mathrm{R}^{2}$ & AIC \\
\hline Null model & & 135 & & & & 388.9 \\
Phylogeny ignored & & & & & & \\
$\quad$ Current distribution & + & 1,134 & 48.62 & $* .22$ & 0.266 & 348.8 \\
$\quad$ Distribution change & + & 1,134 & 6.22 & $* .048$ & 384.8 \\
$\quad$ Relative change & + & 1,134 & 10.81 & $* *$ & 0.075 & 380.4 \\
Controlled for phylogeny & & & & & \\
$\quad$ Current distribution & $+/$ & 2,133 & 22.63 & $* * *$ & 0.254 & 353.1 \\
$\quad$ Distribution change & + & 1,134 & 2.57 & 0.06 & 0.055 & 383.5 \\
$\quad$ Relative change & + & 1,134 & 6.56 & $*$ & 0.047 & 384.4 \\
\hline
\end{tabular}

+- linear response of dependent variable; $+/+-$ increasing quadratic response. 

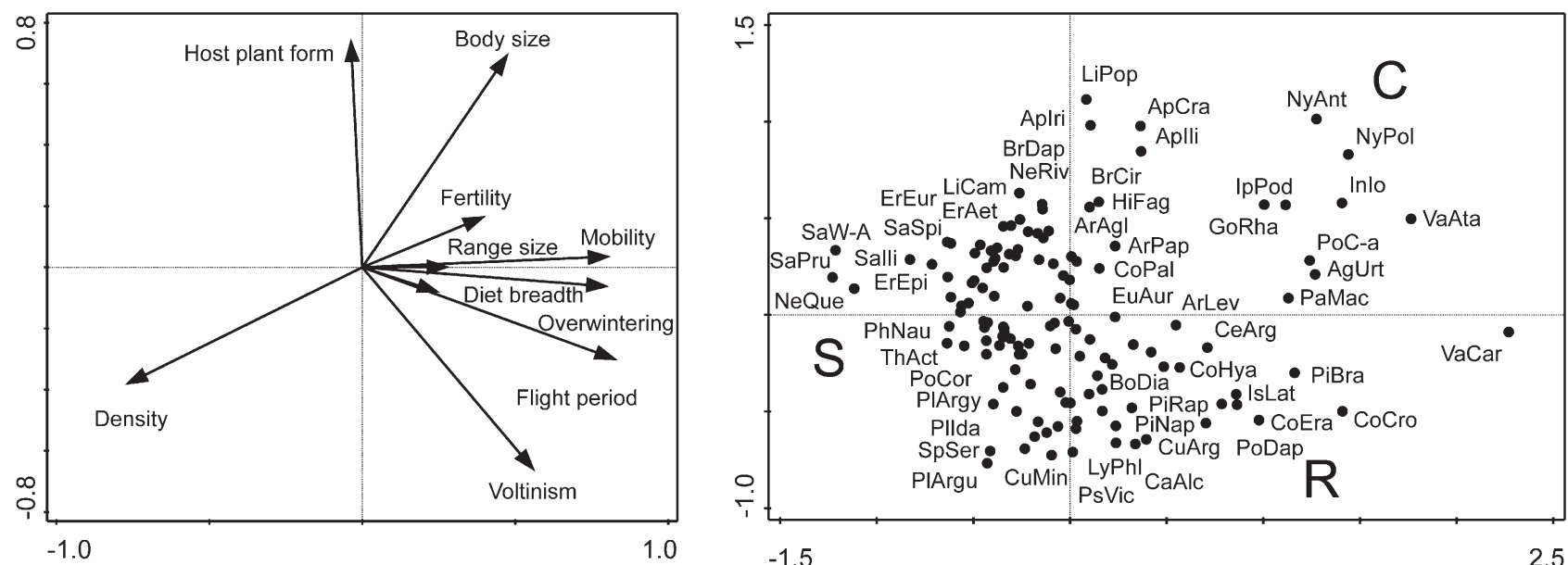

$-1.5$
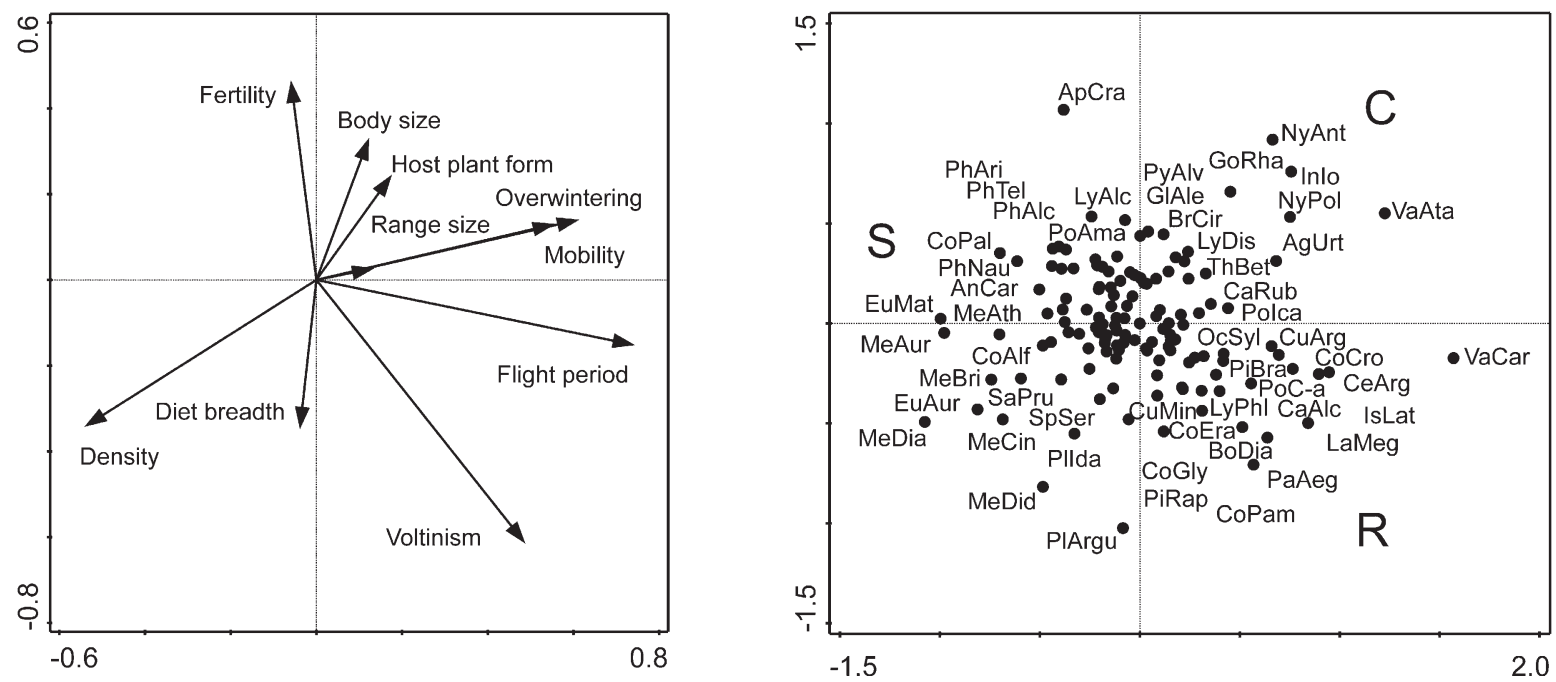

Fig. 1. PCA diagrams (axes 1 and 2) showing ordinations of 136 species of Czech butterflies based on their life history traits. Upper row: ordination not constrained by phylogeny; lower row: ordination constrained by phylogeny. Traits are in the left panel, butterfly species in the right panel. Positions of all species are visualised, but only selected species are named. See Table 1 for positions of all species. The suggested positions of C-S-R strategies of species' host plants are outlined. Species abbreviations: AgUrt - Aglais urticae, AnCar - Anthocharis cardamines, ApCra - Aporia crataegi, ApIli - Apatura Ilia, ApIri - A. iris, ArAgl - Argynnis aglaja, ArLev - Araschnia levana, ArPap - Argynnis paphia, BoDia - Boloria dia, BrCir - Brintesia circe, BrDap - Brenthis daphne, CaAlc - Carcharodus alceae, CaRub - Calophrys rubi, CeArg - Celastrina argiolus, CoAlf - Colias alfacariensis, CoCro - C. crocea, CoEra - C. erate, CoGly - Coenonympha glycerion, CoHya - Colias hyale, CoPal - C. palaeno, CuArg - Cupido argiades, CuMin - C. minimus, ErAet - Erebia aethiops, ErEpi - E. epiphron, EuAur - Euphydryas aurinia, EuEur - Erebia euryale, EuMat - Euphydryas maturna, GlAle - Glaucopsyche alexis, GoRha - Gonepteryx rhamni, HiFag - Hipparchia fagi, InIo - Inachis io, IsLat - Issoria lathonia, LaMeg - Lasiommata megera, LiCam - Limenitis camilla, LiPop - Limenitis populi, LyAlc - Lycaena alciphron, LyDis - L. dispar, LyPhl - L. phleas, MeAth - Melitaea athalia, MeAur - M. aurelia, MeBri - M. britomartis, MeCin - M. cinxia, MeDia - M. diamina, MeDid - M. didyma, NeQue - Neozephyrus quercus, NeRiv - Neptis rivularis, NyAnt - Nymphalis antiopa, NyPol - N. polychloros, OcSyl - Ochlodes sylvanus, PaMac - Papilio machaon, PhAri - Phengaris arion, PhNau - P. nausithous, PhTel - P. teleius, PiBra - Pieris brassicae, PiNap - P. napi, PiRap - P. rapae, PlArgu - Plebejus argus, PlArgy - P. argyrognomon, PlIda - P. idas, PoAma Polyommatus amandus, PoC-a - Polygonia c-album, PoCor - Polyommatus coridon, PoDap - Pontia daplidice, PoIca - Polyommatus icarus, PsVic - Pseudophilotes vicrama, PyAlv - Pyrgus alveus, SaIli - Satyrium ilicis, SaPru - S. pruni, SaSpi - S. spini, SaW-a - S. w-album, SpSer - Spialia sertorius, ThAct - Thymelicus acteon, ThBet - Thecla betulae, VaAta - Vanessa atalanta, VaCar - V. cardui.

proportion of the variation, distinguished between largebodied species developing on apparent host plants with few generations per year, and small-bodied species developing on non-apparent plants with many generations per year.

Correction for phylogeny resulted in PCA axes explaining $29.76 \%, 17.11 \%, 14.70 \%$ and $11.09 \%$ of the variation, with the sum of all eigenvalues 0.602 . Phylogeny thus explains 0.398 of the original variation in the data. Axis 1 (Fig. 1 lower row) correlated positively with length of the flight period (0.735), mobility (0.605), overwintering stage (0.549), voltinism (0.483), host plant form (0.171), range size $(0.127)$ and body size $(0.120)$; and negatively with density $(-0.534)$, diet breadth $(-0.038)$ and fertility $(-0.058)$. Axis 2 correlated positively with fertility (0.457), body size (0.324), host plant form (0.239), mobility (0.139), overwintering stage (0.129) and range size (0.025); negatively with voltinism $(-0.609)$, diet breadth $(-0.340)$, density $(-0.338)$ and length of flight period $(-0.151)$. Axis 1 

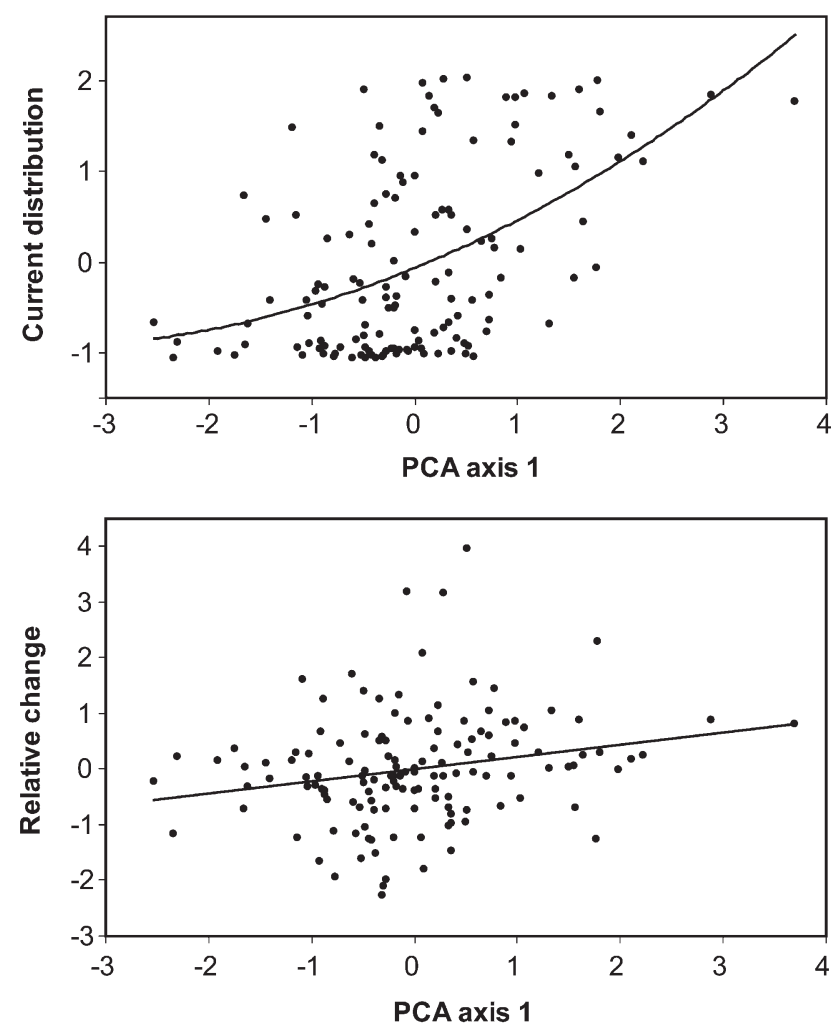

Fig. 2. Regressions relating current distribution (top) and relative change (bottom) of 136 species of Czech butterflies to the generalist-specialist continuum (PCA axis 1, specialists on the left) derived by phylogeny-controlled ordination analysis of the butterflies' life history traits. Current distribution was expressed as the number of map grid squares with records for the period 2002-2013, relative change is the change in the percentage number of squares occupied between 1950-2001 and 2002-2013. Values on both axes were standardised to zero mean and unit variation. See table 3 for regression statistics.

thus again formed a generalist-specialist gradient, whereas axis 2 distinguished between highly fertile, large-bodied species with few generations per year that developed on apparent host plants; and low-fertility, small-bodied species, developing mainly on herbaceous plants.

To check if the missing values for fertility and density influenced the results, we repeated both analyses for the 102 species for which the trait values were available (cf. Table 1). Both the ordination not controlled (explained variability by four axes: $45.17 \%, 16.83 \%, 14.40 \%$ and $6.31 \%$ ) and controlled for phylogeny $(46.17 \%, 17.71 \%, 10.60 \%$, $7.51 \%$, sum of all eigenvalues 0.571 ) returned identical patterns to the analyses including all species.

Values for individual species on PCA axis 1, i.e. on the generalist-specialist continuum, were related to all three status measures, with linear models always achieving the best fit, but explaining a relatively low percentage of the response variation (Table 3). The results were similar after correction for phylogeny, except for current distribution being better fitted by the quadratic model (Fig. 2), which was nevertheless only slightly better than the corresponding linear model $(\triangle \mathrm{AIC}=0.1)$. No status measure was significantly related to PCA axis 2 .

\section{DISCUSSION}

The main gradient in the life history traits of Czech butterflies contrasted highly mobile species overwintering in late stages, with long flight periods and, many generations per year, existing at low densities locally; and species displaying the opposite traits, thus revealing the generalistspecialist continuum detected by other authors (e.g., Stefanescu et al., 2011; Carnicer et al., 2013). Particularly tight correlations were those between mobility and late overwintering stage, probably because surviving the winter in late stages ensures earlier dispersal in spring and more time for exploitation during the year (Boerschig et al., 2013). Generalists tend to have a long flight period, which can be achieved by either a prolonged adult life span, or being polyvoltine. Although the values for diet breadth, range size and fertility, were higher for generalists they contributed rather weakly to the ordination. On the other hand, specialists manifested high population densities locally, which were negatively correlated with mobility and range sizes. The negative population density-mobility relationship (Cowley et al., 2001; Konvicka et al., 2012) probably reflects the dichotomy between species depending on sparsely and unpredictably distributed resources and profiting from wide landscape exploration, and species using clustered resources and existing in dense populations in natal patches. The negative relationship between density and range size contrasts with frequent observations of a positive (local) abundance-occupancy relationship (Brown, 1984; Gaston et al., 2000). Inverse situations, however, appear to be neglected too often in butterfly studies (Paivinen et al., 2005; Komonen et al., 2009; Boerschig et al., 2013). Possibly, the abundance-occupancy relationship, originally recorded for vertebrates, depends on the scale of observation (as shown for butterflies by Cowley et al., 2001; and discussed in general terms by Schwanghart et al., 2008), or on life history peculiarities of various taxa.

Canonical axis 2 explained more than half of the variation in life history traits compared to the generalist-specialist continuum, revealing another important gradient. It contrasted small butterflies with many generations per year, occurring at high densities, utilising non-apparent host plants; and mostly univoltine large-bodied butterflies living at low densities and utilising apparent host plants. This axis of variation, for which we propose the name "constrained voltinism continuum", may reflect the effects of plant antiherbivore strategies on butterfly voltinism. Apparent plants such as trees or grasses tend to utilise nonspecific mechanical defences, such as phenolic macromolecules or silica, whereas non-apparent plants, such as small herbaceous plants, tend to synthesize highly specific noxious chemicals (Feeny, 1976). Rather than being directly poisonous to insect herbivores, mechanical defences constrain the annual numbers of generations either via slowing down herbivore development, or by limiting larval feeding to (short) periods of the year when fresh foliage is available (Cizek, 2005; Cizek et al., 2006; Altermatt, 2010). When the numbers of generations is thus constrained, a species can increase its fitness by growing 
large, a trait positively correlated with fertility (GarciaBarros, 2000). Correspondingly, large size itself may be a prerequisite for feeding on plants protected by quantitative defences (Cizek, 2005). Notably, the constrained voltinism continuum somehow contradicts the $r$-K selection dichotomy (cf. Pianka, 1970), because it lumps high individual fertility ( $r$-trait) with large body size (K-trait) on the one hand, and multiple generations plus high density ( $r$-traits) on the other hand.

Controlling for phylogeny diminished the effect of body size on the generalist-specialist continuum, possibly reflecting the phylogenetic conservatism of this trait. It also disclosed that diet breadth increases towards negative values of the constrained voltinism continuum, i.e. towards species not constrained by the quantitative defences of their hosts. Such species tend to utilise plants from a wider range of families. Garcia-Barros (2000) failed to detect a positive relationship between diet breadth and body size in analyses controlled for phylogeny; we found the opposite effect. Diet breadth, however, is a notoriously problematic trait in Lepidopteran ecology, sensitive to specific delimitation of trophic categories (operational definitions of monophages, oligophages etc.), inclusion of total versus regional host plant spectra and gaps in the knowledge of host plant ranges (cf. Singer et al., 2002; Dennis et al., 2008).

In both phylogenetically uncontrolled and controlled analyses, generalists display wider scatter along the constrained voltinism continuum than tightly clustered specialists, resulting in a roughly triangular distribution of species in ordination diagrams (Fig. 1). Given that host plant apparency increases towards positive values along the constrained voltinism axis, this situation suggests that the link between butterfly and host plant life histories, which was previously suggested for British butterflies (Dennis et al., 2004), also applies to a species-richer Central European fauna. The small bodied multivoltine butterflies (SE corner of the ordination diagrams) all develop on shortlived herbaceous plants, often associated with disturbed ground and sometimes grown as crops, i.e., R-selected plants. This includes e.g., migratory species of the genus Colias Fabricius, 1807, feeding on Fabaceae herbaceous plants, and species of the genus Pieris Schrank, 1801, feeding on Brassicaceae herbaceous plants. The large-bodied univoltine species (NE corner of the diagram) develop on apparent plants, which often dominate their habitats, i.e. $\mathrm{C}$-selected plants. Examples are Iphiclides podalirius (Linnaeus, 1758) feeding on Rosaceae shrubs, Brinthesia circe (Fabricius, 1775) feeding on coarse steppe grasses, or large forest-dwelling nymphalids feeding on trees (cf. Nylin et al., 2014). The dense cluster of specialists (negative values on ordination axis 1) is formed by species inhabiting such disparate habitats as dry grasslands, rocks, alpine tundra, heaths and bogs. A shared feature of such habitats is a high level of environmental stress, tolerated by S-selected plants. The insular distribution of such habitats increases the cost of emigration, which is associated with these species existing at high population densities, whereas factors such as a short vegetation season (due to drought, high altitudes etc.) or low nutritional value of plant tissues restrict the annual number of generations.

Similar to earlier comparisons of species' traits and distribution trends (Kotiaho et al., 2005; Ockinger et al., 2010; Mattila et al., 2011; Franzen et al., 2012), the generalist-specialist continuum correlated with all three status measures tested. Generalists occupy more grid squares and the distribution change of specialists is negative. However, these relationships are weak, due to the wide scatter of status measures over the middle section of the PCA axis, making the generalist-specialist continuum a poor predictor of species conservation status. Middle positions on the continuum encompass a wide diversity of developmental constraints, host plant forms and threat levels, from multivoltine herbaceous plant consumers either non-declining, e.g., Polyommatus icarus (Rottemburg, 1775), or declining, e.g. Pseudophilotes vicrama (Moore, 1865); through medium-sized univoltine herbaceous plant consumers, non-declining, e.g., Anthocharis cardamines (Linnaeus, 1758), or declining, e.g. Euphydryas aurinia (Rottemburg, 1775); large-sized univoltine grass consumers, non-declining, e.g., Brinthesia circe, declining, e.g., Chazara briseis (Linnaeus, 1764), Hipparchia fagi (Scopoli, 1763); to large univoltine tree foliage consumers, typically non-declining, e.g., Apatura ilia (Denis \& Schiffermüller, 1775), Limenitis populi (Linnaeus, 1758). The constrained voltinism continuum was completely unrelated to conservation status.

Dapporto \& Dennis (2013) obtained, for British butterflies, a U-shaped response of threat levels to the generalistspecialist continuum, indicating most rapid declines are recorded for mid generalists, i.e. species with middle values on PCA axis 1. The British fauna, however, is species poor compared with the European mainland, lacking, if compared with Central Europe, several large canopy dwelling nymphalids (e.g., Limenitis populi, Apatura ilia) and large grass-feeding satyrines (e.g., Hipparchia fagi, Brinthesia circe). Analyzing a species-richer fauna both revealed a second important gradient in life histories and masked the fact that some of the most rapidly declining Czech butterflies are also mid generalists. The simple generalist-specialist model thus fails to generate a robust prediction of species conservation status for a moderately species rich Central European country. The attractive C-S-R model does not contribute much either, except for revealing that the non-declining generalists tend to be either $\mathrm{C}$ or $\mathrm{R}$ selected species.

Analyses, like the one presented here may depend on a thorough knowledge of individual species life histories. Such knowledge is still fragmentary, even for much studied European butterflies, especially if within-species regional variation is considered (Dennis et al., 2008). Gaps in knowledge become particularly apparent when compared with studies such as Dapporto \& Dennis (2013) on the globally best known but species poor British butterfly fauna. Trait analyses, by definition, seek to simplify com- 
plex situations and hence should be robust even if there are minor gaps in knowledge.

It should be remembered that the generalist-specialist continuum represents precisely such a simplification. It remains the best model relating butterfly threat status to their life histories, but should be approached with the understanding that the picture is in fact more complex, because the conservation status of individual species may be affected by many other factors. Prominent among such factors are developmental constraints imposed on species by their host plant antiherbivore strategies. Consequently, the loose group of mid generalists may include species that are both common and rapidly declining.

ACKNOWLEDGEMENTS. The study was supported by the Czech Science Foundation (P505/10/2167) and the Grant Agency of the University of South Bohemia (650/3115). We would like to thank the thousands of contributors to CBMR, Z. Faltynek Fric for help with the phylogeny assessment, $M$. Nemec for the graphics, J. Beck and two anonymous reviewers for valuable comments.

\section{REFERENCES}

AKAIKE H. 1974: A new look at the statistical model identification. - IEEE Trans. Autom. Control 19: 716-723.

Altermatt F. 2010: Tell me what you eat and I'll tell you when you fly: diet can predict phenological changes in response to climate change. - Ecol. Lett. 13: 1475-1484.

Aubert J., Legal L., Descimon H. \& Michel F. 1999: Molecular phylogeny of swallowtail butterflies of the tribe Papilionini (Papilionidae, Lepidoptera). - Mol. Phylogenet. Evol. 12: 156-167.

Barbaro L. \& van Halder I. 2009: Linking bird, carabid beetle and butterfly life-history traits to habitat fragmentation in mosaic landscapes. - Ecography 32: 321-333.

BeCK J. \& Fiedler K. 2009: Adult life spans of butterflies (Lepidoptera: Papilionoidea + Hesperioidea): broad-scale contingencies with adult and larval traits in multi-species comparisons. - Biol. J. Linn. Soc. 96: 166-184.

Benes J., Konvicka M., DvoraK J., Fric Z., Havelda Z., PavLicko A., VRabec V. \& Weidenhoffer Z. 2002: Butterflies of the Czech Republic: Distribution and Conservation I, II. SOM, Praha, 857 pp.

Boerschig C., Klein A.-M., von Wehrden H. \& Krauss J. 2013: Traits of butterfly communities change from specialist to generalist characteristics with increasing land-use intensity. $-\mathrm{Ba}$ sic Appl. Ecol. 14: 547-554.

Boggs C.L., Watt W.B. \& Ehrlich P.R. 2003: Butterflies: Ecology and Evolution Taking Flight. University of Chicago Press, Chicago, 739 pp.

Braby M.F., Vila R. \& Pierce N.E. 2006: Molecular phylogeny and systematics of the Pieridae (Lepidoptera: Papilionoidea) higher classification and biogeography. - Zool. J. Linn. Soc. 147: 239-275.

Brown J.H. 1984: On the relationship between abundance and distribution of species. - Am. Nat. 124: 255-279.

Carnicer J., Stefanescu C., Vila R., Dinca V., Font X. \& PenueLAS J. 2013: A unified framework for diversity gradients: the adaptive trait continuum. - Glob. Ecol. Biogeogr. 22: 6-18.

Caterino M.S., Reed R.D., Kuo M.M. \& Sperling F.A. 2001: A partitioned likelihood analysis of swallowtail butterfly phylogeny (Lepidoptera: Papilionidae). — Syst. Biol. 50: 106-127.
CizeK L. 2005: Diet composition and body size in insect herbivores: why do small species prefer young leaves? - Eur. J. Entomol. 102: 675-681.

Cizek L., Fric Z. \& Konvicka M. 2006: Host plant defences and voltinism in European butterflies. - Ecol. Entomol. 31: 337 344.

Cowley M.J.R., Thomas C.D., Roy D.B., Wilson R.J., LeonCortes J.L., Gutierrez D., Bulman C.R., Quinn R.M., Moss D. \& GASTON K.J. 2001: Density-distribution relationships in British butterflies. I. The effect of mobility and spatial scale. J. Anim. Ecol. 70: 410-425.

DAPPORTO L. \& DenNIS R.L.H. 2013: The generalist-specialist continuum: Testing predictions for distribution and trends in British butterflies. - Biol. Conserv. 157: 229-236.

Dennis R., Williams W. \& Shreeve T. 1991: A multivariate approach to the determination of faunal structures among European butterfly species (Lepidoptera, Rhopalocera). - Zool. J. Linn. Soc. 101: 1-49.

Dennis R.L.H., Hodgson J.G., Grenyer R., Shreeve T.G. \& Roy D.B. 2004: Host plants and butterfly biology. Do host-plant strategies drive butterfly status? - Ecol. Entomol. 29: 12-26.

Dennis R.L.H., Hardy P.B. \& Shreeve T.G. 2008: The importance of resource databanks for conserving insects: a butterfly biology perspective. - J. Insect. Conserv. 12: 711-719.

Dennis R.L.H., Dapporto L., Fattorini S. \& CoOK L.M. 2011: The generalism-specialism debate: the role of generalists in the life and death of species. - Biol. J. Linn. Soc. 104: 725-737.

Eliot J.N. 1973: The higher classification of the Lycaenidae (Lepidoptera): A tentative arrangement. - Bull. Br. Mus. Nat. Hist. (Entomol.) 28: 371-505.

FeEny P. 1976: Plant apparency and chemical defense. - Rec. Adv. Phytochem. 10: 1-40.

Franzen M. \& Betzholtz P.-E. 2012: Species traits predict island occupancy in noctuid moths. - J. Insect Conserv. 16: 155-163.

Franzen M., Schweiger O. \& Betzholtz P.-E. 2012: Species-area relationships are controlled by species traits. - PLoS One 7: e37359.

Garcia-Barros E. 2000: Body size, egg size, and their interspecific relationships with ecological and life history traits in butterflies (Lepidoptera : Papilionoidea, Hesperioidea). — Biol. J. Linn. Soc. 70: 251-284.

Garcia-Barros E. \& Romo B.H. 2010: The relationship between geographic range size and life history traits: is biogeographic history uncovered? A test using the Iberian butterflies. Ecography 33: 392-401.

Gaston K.J., Blackburn T.M., Greenwood J.J.D., Gregory R.D., QuinN R.M. \& LawTon J.H. 2000: Abundance-occupancy relationships. - J. Appl. Ecol. 37: 39-59.

GRIME J.P. 1977: Evidence for the existence of three primary strategies in plants and its relevance to ecological and evolutionary theory. - Am. Nat. 111: 1169-1194.

Habel J.C. \& Schmitt T. 2012: The burden of genetic diversity. - Biol. Conserv. 147: 270-274.

Habel J.C., Roedder D., Lens L. \& Schmitt T. 2013: The genetic signature of ecologically different grassland Lepidopterans. Biodivers. Conserv. 22: 2401-2411.

Higgins L.G. \& Riley N.D. 1970: A Field Guide to the Butterflies of Britain and Europe. Collins, London, 380 pp.

Jonason D., Andersson G.K.S., Ockinger E., Rundlof M., SMith H.G. \& Bengtsson J. 2011: Assessing the effect of the time since transition to organic farming on plants and butterflies. J. Appl. Ecol. 48: 543-550. 
Koh L.P., Sodhi N.S. \& BRooK B.W. 2004: Ecological correlates of extinction proneness in tropical butterflies. - Conserv. Biol. 18: $1571-1578$.

Komonen A., Grapputo A., Kaitala V., Kotiaho J.S. \& Paivinen J. 2004: The role of niche breadth, resource availability and range position on the life history of butterflies. - Oikos 105: $41-54$.

Komonen A., Paivinen J. \& Kotiaho J.S. 2009: Missing the rarest: is the positive interspecific abundance-distribution relationship a truly general macroecological pattern? - Biol. Lett. 5: 492-494.

Konvicka M., Zimmermann K., Klimova M., Hula V. \& Fric Z. 2012: Inverse link between density and dispersal distance in butterflies: field evidence from six co-occurring species. Popul. Ecol. 54: 91-101.

Kotiaho J.S., Kaitala V., Komonen A. \& Paivinen J. 2005: Predicting the risk of extinction from shared ecological characteristics. - PNAS 102: 1963-1967.

Lizee M.-H., Mauffrey J.-F., Tatoni T. \& Deschamps-Cottin M. 2011: Monitoring urban environments on the basis of biological traits. - Ecol. Indic. 11: 353-361.

MacArthur R.H. \& Wilson E.O. 1967: The Theory of Island Biogeography. Princeton University Press, Princeton, NJ, 203 pp.

Mattila N., Kaitala V., Komonen A., Kotiaho J.S. \& Paivinen J. 2006: Ecological determinants of distribution decline and risk of extinction in moths. - Conserv. Biol. 20: 1161-1168.

Mattila M., Kotiaho J.S., Kaitala V. \& Komonen A. 2008: The use of ecological traits in extinction risk assessments: A case study on geometrid moths. - Biol. Conserv. 141: 2322-2328.

Mattila N., Kaitala V., Komonen A., Paivinen J. \& Kotiaho J.S. 2011: Ecological correlates of distribution change and range shift in butterflies. - Insect Conserv. Diver. 4: 239-246.

McGill B.J., Enquist B.J., Weiner E. \& Westoby M. 2006: Rebuilding community ecology from functional traits. - Trends Ecol. Evol. 21: 178-185.

Menendez R., Gonzalez-Megias A., Collingham Y., Fox R., Roy D.B., Ohlemuller R. \& Thomas C.D. 2007: Direct and indirect effects of climate and habitat factors on butterfly diversity. Ecology 88: 605-611.

Nylin S., Slove J. \& JanZ N. 2014: Host plant utilization, host range oscillations and diversification in nymphalid butterflies: a phylogenetic investigation. - Evolution 68: 105-124.

Ockinger E., Schweiger O., Crist T.O., Debinski D.M., Krauss J., Kuussaari M., Petersen J.D., Poyry J., Settele J., SumMERVILLE K.S. \& BOMMARCO R. 2010: Life-history traits predict species responses to habitat area and isolation: a cross-continental synthesis. - Ecol. Lett. 13: 969-979.

Paivinen J., Grapputo A., Kaitala V., Komonen A., Kotiaho J.S., SAARINEN K. \& Wahlberg N. 2005: Negative density-distribution relationship in butterflies. - BMC Biology 3: 5.

PiANKA E. 1970: R-Selection and K-Selection. - Am. Nat. 104: $581-588$

Poeyry J., Luoto M., Heikkinen R.K., Kuussaari M. \& SaArinen K. 2009: Species traits explain recent range shifts of Finnish butterflies. - Glob. Change Biol. 15: 732-743.

R Core TEAm 2013: R: A Language and Environment for Statistical Computing. Vienna, Austria, R Foundation for Statistical Computing. URL: http://www.R-project.org/.
Reinhardt R., Sbieschne H., Settele J., Fischer U. \& Fiedler G. 2007: Tagfalter von Sachsen. In Klausnitzer B. \& Reinhardt R. (eds): Beiträge zur Insektenfauna Sachsens Band 6. Entomologische Nachrichten und Berichte, Beiheft 11. Dresden, 696 pp.

Rundlof M. \& Sмiтн H.G. 2006: The effect of organic farming on butterfly diversity depends on landscape context. - J. Appl. Ecol. 43: 1121-1127.

Schwanghart W., Beck J. \& Kuhn K. 2008: Measuring population densities in a heterogeneous world. - Global Ecol. Biogeogr. 17: 566-568.

SEKAR S. 2012: A meta-analysis of the traits affecting dispersal ability in butterflies: can wingspan be used as a proxy? $-J$. Anim. Ecol. 81: 174-184.

Singer M.C., Stefanescu C. \& Pen I. 2002: When random sampling does not work: standard design falsely indicates maladaptive host preferences in a butterfly. - Ecol. Lett. 5: 1-6.

SogA M. \& KoIKE S. 2013: Mapping the potential extinction debt of butterflies in a modern city: implications for conservation priorities in urban landscapes. - Anim. Conserv. 16: 1-11.

Stefanescu C., Carnicer J. \& Penuelas J. 2011: Determinants of species richness in generalist and specialist Mediterranean butterflies: the negative synergistic forces of climate and habitat change. - Ecography 34: 353-363.

Stevens V.M., Trochet A., Van Dyck H., Clobert J. \& Baguette M. 2012: How is dispersal integrated in life histories: a quantitative analysis using butterflies. - Ecol. Lett. 15: 74-86.

Telfer M.G., Preston C.D. \& Rothery P. 2002: A general method for measuring relative change in range size from biological atlas data. - Biol. Conserv. 107: 99-109.

Ter Braak C.J.F. \& Smilauer P. 2012: CANOCO Reference Manual and User's Guide: Software for Ordination (version 5.0). Microcomputer Power, Ithaca, NY, 496 pp.

Tolman T. \& Lewington R. 2008: Collins Butterfly Guide: The Most Complete Field Guide to the Butterflies of Britain and Europe. Collins, London, 384 pp.

Turlure C., Schtickzelle N. \& Baguette M. 2010: Resource grain scales mobility and adult morphology in butterflies. Landsc. Ecol. 25: 95-108.

Wahlberg N., Weingartner E. \& Nylin S. 2003: Towards a better understanding of the higher systematics of Nymphalidae (Lepidoptera: Papilionoidea). - Mol. Phylogenet. Evol. 28: 473-484.

WALton R.K., BROWER L.P. \& DAVIS A.K. 2005: Long-term monitoring and fall migration patterns of the Monarch butterfly in Cape May, New Jersey. - Ann. Entomol. Soc. Am. 98: 682689.

WARREN M.S. 1992: Butterfly populations. In Dennis R.L.H. (ed.): The Ecology of Butterflies in Britain. Oxford University Press, Oxford, pp. 73-92.

Warren A.D., Ogawa J.R. \& Brower A.V.Z. 2009: Revised classification of the family Hesperiidae (Lepidoptera: Hesperioidea) based on combined molecular and morphological data. - Syst. Entomol. 34: 467-523.

Woodcock B.A., Bullock J.M., Mortimer S.R., Brereton T., Redhead J.W., Thomas J.A. \& Pywell R.F. 2012: Identifying time lags in the restoration of grassland butterfly communities: A multi-site assessment. — Biol. Conserv. 155: 50-58.

Received February 2, 2014; revised and accepted May 26, 2014 Prepublished online August 13, 2014 